\title{
El Papel Directivo y la Promoción de la Participación de las Familias y la Comunidad en las Escuelas Básica. El Caso de la Comuna de Panguipulli-Chile
}

\author{
Leadership Role and Promoting the Participation of Families \\ and the Community in Basic Schools. The Case of Panguipulli- \\ Chile
}

\author{
Claudio Barrientos Piñeiro ${ }^{1 *}$ \\ Patricia Silva García ${ }^{2}$ \\ Serafín Antúnez Marcos ${ }^{1}$ \\ ${ }^{1}$ Universidad de Barcelona ${ }^{2}$ Universidad de Lleida
}

\begin{abstract}
El presente texto aporta valiosa información acerca del desempeño directivo en relación con las características y orientaciones que se le concede a la participación de las familias y la comunidad en la vida de las escuelas básicas de Panguipulli. Presentamos un Estudio de Casos a través de un enfoque cualitativo en que se hacen visibles elementos del contexto sociocultural y geográfico que enfrenta la gestión directiva y que repercuten directamente en favorecer o dificultar dicha promoción dentro del territorio estudiado. Describe y analiza visiones y formas de hacer, identificando las principales actividades, modalidades y formas de participación. Este conocimiento aporta un sustento teórico referencial y unos resultados empírico sustanciales de una realidad particular, que se traduce en una contribución a la discusión académica como insumo para en el fortalecimiento de esta dimensión.
\end{abstract}

Descriptores: Participación, Familias, Comunidad, Dirección escolar, Liderazgo.

\begin{abstract}
This text provides valuable information about management performance in relation to the characteristics and guidance is given to the participation of families and the community in the life of basic schools Panguipulli. We present a case study through a qualitative approach that visible elements of cultural and geographical context facing executive management and directly affect favor or hinder such promotion within the territory studied are made. It describes and analyzes visions and ways of identifying the main activities, methods and forms of participation. This knowledge provides a referential theoretical support and substantial empirical results of a particular reality, which translates into a contribution to the academic discussion as input for the strengthening of this dimension.
\end{abstract}

Keywords: Participation, Family, Community, School management, Leadership.

\footnotetext{
*Contacto: clabapineiro@gmail.com

ISSN: $1696-4713$

www.rinace.net/reice/

revistas.uam.es/reice

Recibido: $\quad 15$ de diciembre 2015

$1^{\text {a }}$ Evaluación: 27 de febrero 2016

$2^{\text {a }}$ Evaluación: 29 de marzo 2016

Aceptado: $\quad 3$ de abril 2016
} 


\section{Introducción}

El papel de los directores de escuelas, como líderes pedagógicos en la gestión de sus centros educativos, ha ido cobrando cada día mayor relevancia, debido a la repercusión e impacto que su desempeño cobra hacia el mejoramiento de la educación. Es una dimensión que ha sido poco estudiado y que requiere de una atención preferente. Un importante estudio realizado en Chile (Weinstein y Muñoz, 2012) deja en evidencia lo poco que sabemos acerca de los directores de escuelas en Chile y el nulo conocimiento que se posee sobre este ámbito de estudio en particular.

Este mundo interconectado y sobre informado, con asentados nuevos modos de hacer y relacionarnos, exige al sistema educativo adoptar nuevas formas de liderazgos y reclamado una mayor corresponsabilidad social sobre la educación, principalmente de parte las familias y las comunidades cercanas, en el convencimiento que hacerse cargo de la tarea de educar no puede -ni debe- ser solo tarea exclusiva de las escuelas. Aquello debe configurarse con la incorporación protagónica de los padres y el entorno social inmediato, otorgando la posibilidad que los agentes educativos puedan involucrarse y aportar sus ideas y fortalezas en la tarea educativa. Esto implica la necesidad de promover una participación pedagógica, liderada por los directores, en quienes recae la responsabilidad sobre la calidad de la educación que sus instituciones entregan y de quienes poco se ha estudiado sobre su desempeño.

Bajo estas ideas, compartimos la necesidad de comprender y fortalecer la labor directiva en torno a la promoción de la participación en las escuelas, para aportar a los procesos de mejora de la dirección y gestión en esta dimensión en particular y en el desempeño y la formación directiva a todo nivel.

\section{Fundamentación teórica}

En estas dos décadas y media de inicio del XXI, más que en cualquier otro período de la historia mundial, los sistemas educativos han reclamado una urgente necesidad de contar con el respaldo incondicional de las familias y sus entornos sociales para enfrentar las complejas circunstancias educativas.

A pesar que la educación focaliza sus esfuerzos en propender al desarrollo integral de las personas, parece ser que esto no ha prosperado como se desea. Los procesos formativos aún "tienden al reduccionismo, enfocándose en una formación que busca adecuarse a las demandas del mercado laboral, las exigencias de la economía o una formación academicista" (Aylwin, 2013, p. 19). Reconociendo algunos avances a nivel mundial, América Latina todavía está en deuda con aquello, aun cuando aspectos fundamentales para el desarrollo humano se abordan de manera parcelada (convivencia, valores, discernimiento ético, otros).

En un mundo consumista y de expansión productiva esta situación parece ser un tema de segundo orden, que es necesario revertir a través de la apertura formativa de las escuelas, las familias y la sociedad en su conjunto para afianzar el compromiso de responsabilidad y corresponsabilidad con la educación de las nuevas generaciones. Aquello permitirá fortalecer los procesos la enseñanza y aprendizaje de los estudiantes, condición que en el actual modelo es cuestionable. 
Reflejo de esto han sido las innumerables reformas implementadas por muchos gobiernos en los últimos quince años. México (OCDE, 2012a); Perú (Morillo, 2002); Chile (Contreras, 2011); España (MECD, 2004) en que paradójicamente, a pesar de los esfuerzos, continúan vigente los exiguos resultados en mediciones estandarizas como PISA (OCDE, 2012b) o el SIMCE en Chile.

El actual escenario social reclama innovaciones en esta dirección. Nos recuerda Tejada (2000) que "los cambios sociales, culturales y económicos inciden de forma determinante en los planteamiento educativos, y como tales, exigen modificaciones estructurales (sistemas educativos) y modificaciones en las propias prácticas" (p. 1), con espacios de aprendizajes más abiertos, democráticos y cohesionados con las realidades locales.

Investigaciones como las de Salimbeni (2011) han demostrado que: “...el rendimiento de los estudiantes y el aprendizaje están influenciados por las interacciones que los estudiantes tienen con todos los actores sociales...que participan en su educación, por lo tanto, el rendimiento estudiantil aumentará, aumentando la participación” (p. 21).

Por su parte, Anderson (1999, citado en Torres, 2001), fundamenta que: “...los defensores de la participación proponen que las familias y comunidades deberían participar en diversas dimensiones del quehacer escolar incluyendo (a) la gestión y la toma de decisiones, (b) la organización para la equidad y la calidad, (c) el currículum y su manejo en el aula, y (d) el apoyo educativo en el hogar”(p. 24).

Abrazamos la idea entonces que esta instancia debe extrapolar a la sola asistencia de las familias en determinadas situaciones escolares, entendiendo que participar "es la acción de intervenir en los procesos de planificación, ejecución y evaluación de determinadas tareas que se desarrollen” (Antúnez, 2000, p. 89).

En estos términos, el Ministerio de Educación de Chile, considerando las aportaciones de Flamey y colaboradores (2005, p. 11-12), ha acogido como referentes en sus políticas de participación cinco niveles de actuaciones (figura 1), lo que deberían ser propiciados por los directores de escuelas.

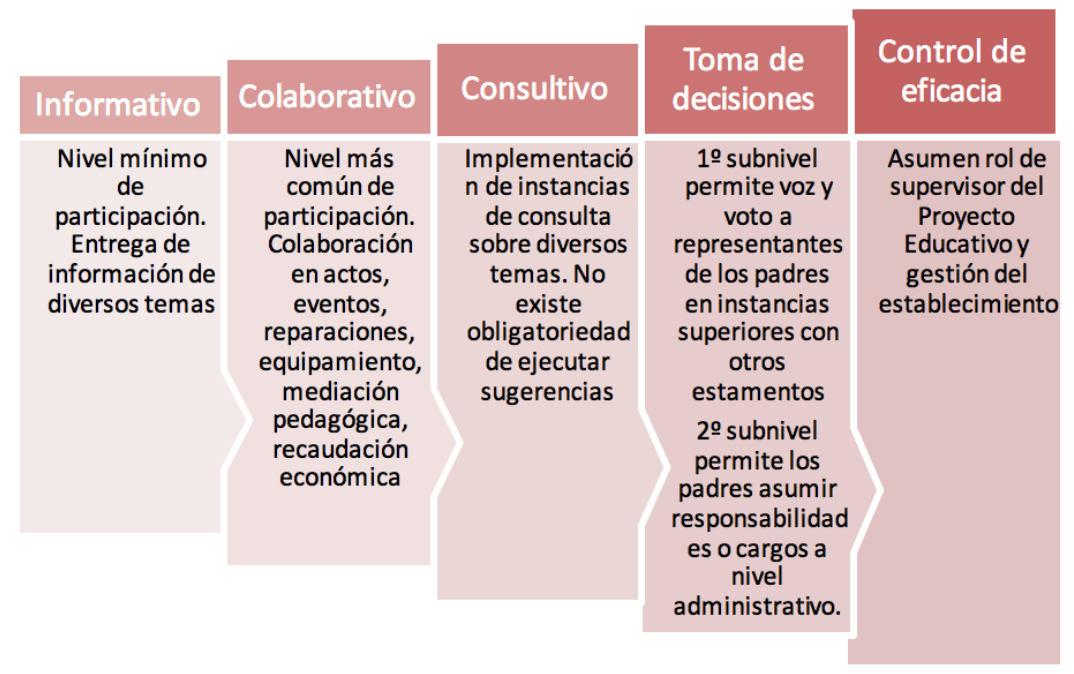

Figura 1. Niveles de participación según Flamey, Gubbins y Morales (1999) Fuente: CIDE (Centro de Investigación y Desarrollo de la Educación). 
Además de lo anterior, creemos conveniente considerar la visión que al respecto de la participación tiene Kidder (2013), quien afirma que: "Treinta años de investigación internacional muestran que lo que los padres hacen en casa es lo más importante para el éxito de los alumnos... En lugar de centrar todos los esfuerzos en conseguir atraer a los padres a la escuela, las escuelas necesitan desarrollar mejores maneras de comunicarse con ellos", situación que de acuerdo a las actuales problemáticas sociales se presenta como una positiva estrategia de considerar.

Figura indisociable y fundamental para poner en juego estos planteamientos es el director quien, según afirma Ball (1994), "es el centro principal de la actividad micropolítica en la escuela” (pp. 92), por tanto deber ser considerado como la figura de influencia determinante al establecer el rumbo de la organización. Es el líder y "el profesional de nivel superior que se ocupa de la dirección, administración, supervisión y coordinación de la educación de la unidad educativa" (Fundación Chile, 2006, p. 2), de quien se necesita que su desempeño y sus competencias personales y profesionales dialoguen con la apertura de espacios de participación, cimentando su gestión bajo principios de corresponsabilidad, cooperación, coordinación y autoridad democrática. Por tanto, su acción debe estar impregnada en la convicción de que "la participación social significa aprender a tomar decisiones conjuntas entre director, maestros, padres y madres de familia y alumnos, así como recibir ayuda y colaboración de ex alumnos y otros actores de la comunidad" (Santizo, 2009, p. 1).

Consecuente con ello, "se observa la conveniencia de instalar nuevos modos de "hacer y vivir la escuela" a los que exige generar propuestas contextualizadas que respondan a las demandas existentes" (Gairín, 2003, p. 22), labor imperiosa que todo director debe llevar adelante, siendo el líder responsable de dirigir, dinamizar y motivar los procesos de participación de todos los actores educativos.

\section{Método}

La investigación se desarrolló con un enfoque cualitativo, desde un paradigma interpretativo, focalizado en un Estudio de Caso con un diseño etnográfico orientado en "describir y analizar ideas, creencias, significados, conocimientos y prácticas de grupos, culturas y comunidades" (Patton, 2002, citado en Hernández et al., 2006, p. 697). Centró su atención en un contexto social natural, cuyo objeto de estudio fue analizado en su dinámica normal, sin manipularlo ni modificarlo.

Nos planteamos como objetivo principal describir, analizar y comprender el papel de los directores de escuelas básicas en relación con la promoción de la participación de las familias y la comunidad con el fin de aportar a los procesos de mejora de la gestión educativa y la participación. Para ello nos sirvieron como fuente principales de información diez directores que se desempeñan en un $90 \%$ en la administración pública a cargo de escuelas con similares características socioeducativas del área urbana y rural, en su mayoría con más de 5 años en sus cargos en la comuna, con quienes realizamos entrevistas semi estructuradas. Igualmente realizamos observaciones no participantes con cinco de los diez directores, con quienes estuvimos en cinco reuniones con padres, en tres de actividades de participación en sus escuelas y en diez en jornadas de un día con ellos. Éstos profesionales conformaron el $100 \%$ de las direcciones de escuelas de la comuna, con lo cual la muestra fuera muy representativa. 
Las fuentes complementarias la constituyeron grupos promedio de seis docentes, asistentes de la educación, padres representantes de Centros Generales de Padres y de la comunidad ligados a las escuelas de desempeño de los directores, con quienes indistintamente se realizaron cuatro grupos de discusión. Finalmente, aplicamos un cuestionario a una muestra de 168 padres, de los cuales un $75 \%$ poseía más de 5 años en dicha responsabilidad y un $76 \%$ lo había ejercido en más de una escuela dentro de la misma comuna, con una edad promedio de 41 años y un $90 \%$ mujeres (figura 2 ).
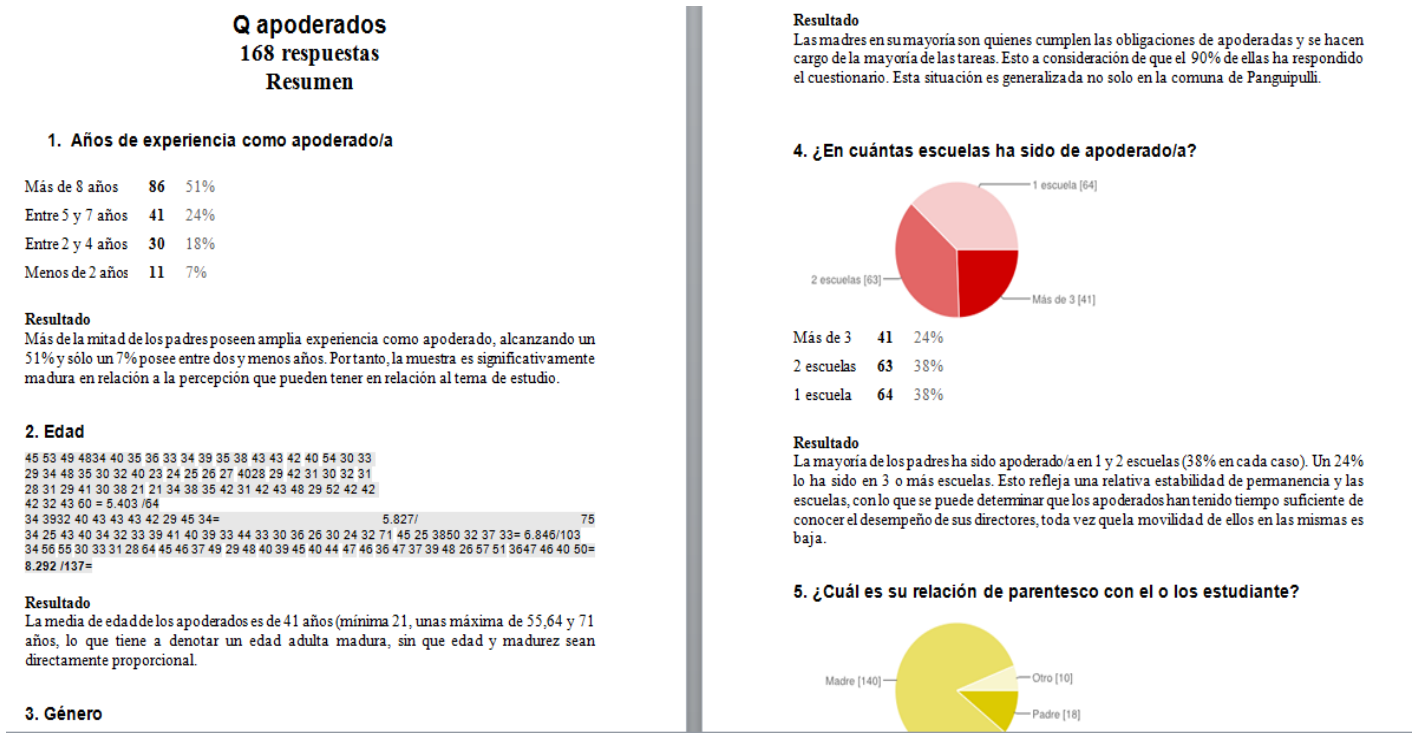

Figura 2. Resultados cuantitativos cuestionarios aplicados a padres Fuente: Elaboración propia.

El análisis de la información de las entrevistas y grupos de discusión fue abordada inductivamente utilizando el programa ATLAS.Ti 7. considerando cuatro niveles de análisis: fragmentación de la información, codificación, categorización y obtención de meta categorías (figura 3).

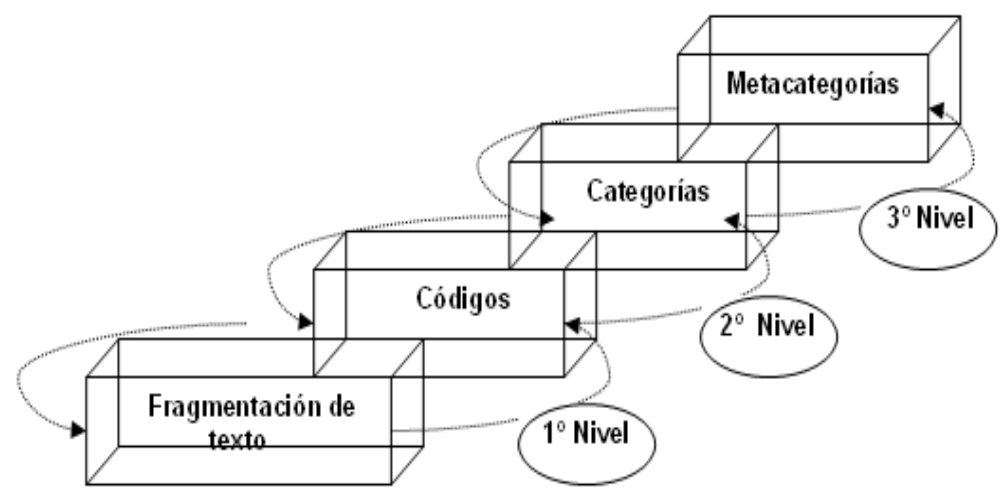

Figura 3. Niveles de análisis para la reducción de información Fuente: Recuperado de Silva (2008). 
En primera instancia, tanto a las entrevistas como grupos de discusión le asignamos un código, sin una identificación directa de persona o estamento, desde donde se obtuvieron las Unidades de Significado. En un $2^{\circ}$ nivel asignamos un código identificatorio a dichas Unidades y posteriormente agrupamos los códigos en categorías de acuerdo a su similitud de sentido semántico, lo que nos llevó a un $3^{\circ}$ nivel. Finalmente, reagrupamos dichas categorías en un $4^{\circ}$ nivel desde donde emergieron las meta categorías que responden a los ejes centrales del estudio (figura 4).

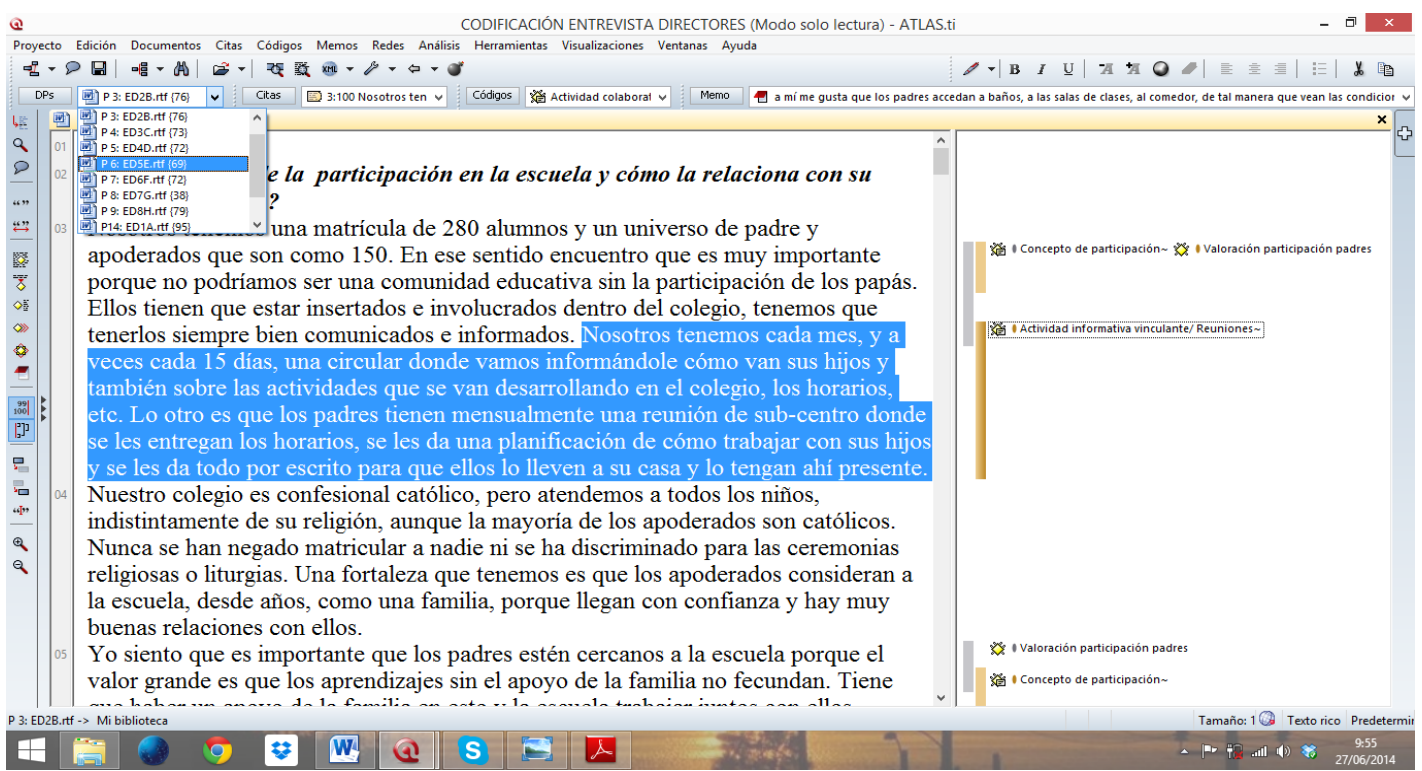

Figura 4. Primer y segundo nivel de análisis: US y códigos Entrevistas Directores en

ATLAS. Ti 7

Fuente: Elaboración propia.

En el transcurso del análisis de la información realizamos agrupación, reagrupación y eliminación de códigos con el objeto de refinar la información obtenida, tomando como referencia los principios orientadores del método comparativo constante (Maykut y Morehouse, 1998, p. 135), representado en la figura 5.

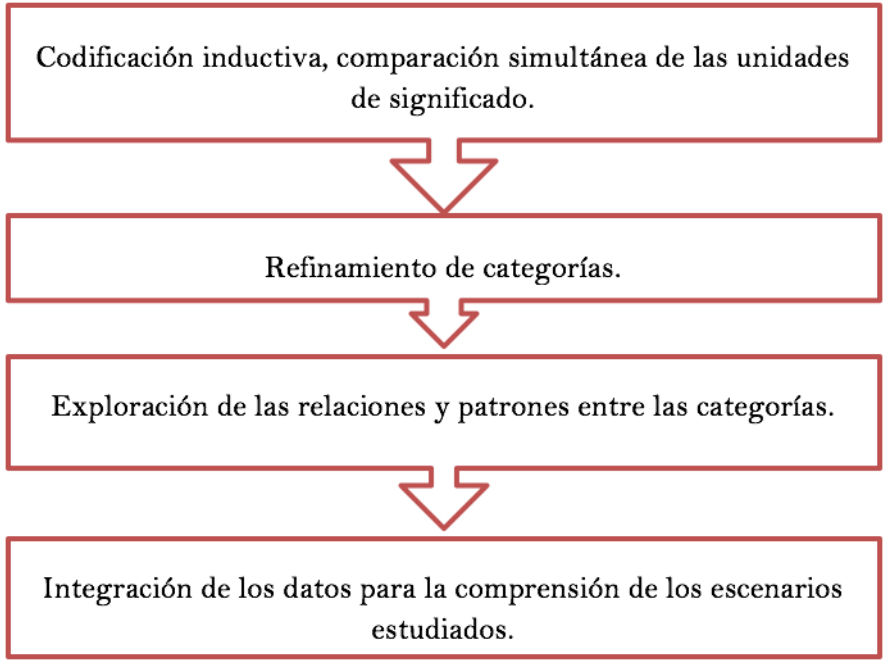

Figura 5. Etapas método comparativo constante Fuente: Elaborado a partir de Maykut y Morehouse (1998). 
Este proceso fue realizado en 5 oportunidades, las cuales arrojaron los resultados expuestos en la tabla 1.

Tabla 1. Resultados fases de refinación de la información

\begin{tabular}{ccc}
\hline FASES & US & CóDIGOS \\
\hline $\mathbf{1}^{\mathbf{o}}$ & 736 & 199 \\
$\mathbf{2}^{\mathbf{o}}$ & 711 & 167 \\
$\mathbf{3}^{\mathbf{o}}$ & 705 & 160 \\
$\mathbf{4}^{\mathbf{o}}$ & 697 & 146 \\
$\mathbf{5}^{\mathbf{o}}$ & 671 & 136 \\
\hline
\end{tabular}

Fuente: Elaboración propia.

Un resumen del trabajo analítico anterior se muestra en la figura 6:

CUADRO RESUMEN DE RESULTADOS NIVELES DE ANÁLISIS

\begin{tabular}{|c|c|c|c|}
\hline Meta categorías & Categorías & US - Códigos y Familias de Códigos & Total US \\
\hline \multirow[t]{6}{*}{$\begin{array}{l}\text { Competencias } \\
\text { profesionales. }\end{array}$} & Competencias habituales & $\begin{array}{l}\text { Competencias directivas - Conocimientos, actitudes. Valores, habilidades } \\
\text { sociales, habilidades personales, liderazgo (104) }\end{array}$ & \multirow[t]{6}{*}{173} \\
\hline & Competencias por fortalecer & Competencias directivas por fortalecer (22) & \\
\hline & Competencias relevantes & Competencias directivas relevantes (16) & \\
\hline & Competencias de un buen director & Características de un buen director (14) & \\
\hline & Valoración de sus competencias & Valoración nivel competencial (10) & \\
\hline & Características directores & Características directores Panguipulli (7) & \\
\hline \multirow[t]{2}{*}{ Visión directiva } & $\begin{array}{l}\text { Concepciones y valoraciones sobre la } \\
\text { participación }\end{array}$ & $\begin{array}{l}\text { Apreciaciones y tendencias de participación de los padres (71) } \\
\text { Valoración de la participación de padres (19) } \\
\text { Concepto de participación (17) } \\
\text { Valoración de la participación (11) } \\
\text { Valoración de la participación de la comunidad (7) } \\
\text { Anhelos directivos de participación (5) }\end{array}$ & \multirow[t]{2}{*}{137} \\
\hline & Implicación en la comunidad & Participación dentro de la comunidad (7) & \\
\hline \multirow[t]{3}{*}{$\begin{array}{l}\text { Actividades de } \\
\text { participación. }\end{array}$} & Variedad de actividades & $\begin{array}{l}\text { Actividades escuela-comunidad (29) } \\
\text { Actividades colaborativas comunidad (22) } \\
\text { Actividades formativas padres (18) } \\
\text { Actividades informativas vinculantes (14) } \\
\text { Actividades resolutivas de padres (9) } \\
\text { Actividades colaborativas de padres escuela (7) }\end{array}$ & \multirow[t]{3}{*}{124} \\
\hline & Objetivos de las actividades & Promoción de valores y actitudes de las actividades (21) & \\
\hline & Efectividad & Efectividad de las actividades (4) & \\
\hline \multirow{2}{*}{$\begin{array}{l}\text { Condicionantes de } \\
\text { contexto. }\end{array}$} & Dificultades & Dificultades promoción de la participación (74) & \multirow[t]{2}{*}{88} \\
\hline & Facilitadores & Facilitadores de la promoción de la participación (14) & \\
\hline \multirow[t]{3}{*}{ Prácticas directivas. } & Prácticas cotidianas & Prácticas directivas habituales (56) & \multirow[t]{3}{*}{85} \\
\hline & Prácticas relevantes & Prácticas directivas relevantes $(9)$ & \\
\hline & Practicas vor imblementar & Drártiese dirertivae nn hahituales (f) & \\
\hline
\end{tabular}

Figura 6. Extracto cuadro resumen final del proceso de codificación

Fuente: Elaboración propia.

A partir de este análisis emergieron las distintas categorías que originaron siete meta categorías relevantes, de las cuales solo la visión directiva, actividades de participación y condicionantes del contexto han sido consideradas para efectos del presente artículo (tabla 2).

Por otra parte, la información obtenida en los cuestionarios de padres se acopió en la aplicación Google form, donde se realizó un análisis manual cualitativo de las respuestas abiertas, en tanto que la información cuantitativa fue tabulada y graficada por la misma aplicación y luego interpretadas cualitativamente (figura 7), con lo que se enriqueció la información obtenida en las entrevistas y grupos de discusión.

Basados en esta información pudimos comprender la realidad del comportamiento idiosincrásico de los participantes, conociendo sus opiniones, actitudes y razones por las que se desenvuelven de una determinada manera en este espacio sociocultural propio, lo que se presenta a continuación. 
Tabla 2. Meta-categorías y definiciones

\begin{tabular}{|c|c|c|}
\hline CódiGo & METACATEGORÍAS & DEFINICIÓN \\
\hline VD & Visión directiva & $\begin{array}{l}\text { Concepciones y valoraciones de los directores en } \\
\text { relación a sus conceptualizaciones, percepciones, } \\
\text { tendencias y proyecciones de la participación de los } \\
\text { padres y la comunidad en la escuela y de su propia } \\
\text { implicación en sus comunidades. }\end{array}$ \\
\hline $\mathbf{C P}$ & $\begin{array}{l}\text { Competencias } \\
\text { profesionales }\end{array}$ & $\begin{array}{l}\text { Conjunto combinado de saberes, habilidades, } \\
\text { destrezas, actitudes, valores, motivaciones y rasgos de } \\
\text { personalidad que articulan y movilizan los directores } \\
\text { en sus prácticas directivas para la efectiva promoción } \\
\text { de la participación de los padres y la comunidad en } \\
\text { sus escuela. }\end{array}$ \\
\hline PD & Prácticas directivas & $\begin{array}{l}\text { Conjunto de comportamientos orientados a la } \\
\text { concreción de la promoción de la participación de las } \\
\text { familias y la comunidad en la escuela. }\end{array}$ \\
\hline EPP & $\begin{array}{l}\text { Estrategias de } \\
\text { promoción de la } \\
\text { participación }\end{array}$ & $\begin{array}{l}\text { Conjunto de acciones planificadas y concretas en que } \\
\text { los directores desentrañan sus modos de hacer con el } \\
\text { propósito de promover la participación de las familias } \\
\text { y la comunidad, movilizando una variedad de } \\
\text { recursos, dispositivos, herramientas y decisiones para } \\
\text { ello. }\end{array}$ \\
\hline AP & $\begin{array}{l}\text { Actividades de } \\
\text { participación }\end{array}$ & $\begin{array}{l}\text { Iniciativas promovidas por los directores, la } \\
\text { comunidad educativa o la comunidad que permiten la } \\
\text { intervención de los padres o agentes educativos en el } \\
\text { quehacer escolar, independiente de su intencionalidad } \\
\text { inclusiva. }\end{array}$ \\
\hline $\mathbf{C C}$ & $\begin{array}{l}\text { Condicionantes del } \\
\text { contexto }\end{array}$ & $\begin{array}{l}\text { Elementos que determinan las ventajas y desventajas } \\
\text { que inciden en la eficiencia de la gestión directiva } \\
\text { para promover la participación de las familias y la } \\
\text { comunidad en las escuelas. }\end{array}$ \\
\hline VAE & $\begin{array}{l}\text { Visiones de los agentes } \\
\text { educativos y la } \\
\text { comunidad }\end{array}$ & $\begin{array}{l}\text { Consideraciones, percepciones y valoraciones de los } \\
\text { docentes, padres, asistentes de la educación y la } \\
\text { comunidad en relación a las competencias } \\
\text { profesionales y desempeño de los directores en } \\
\text { relación a la promoción de la participación de las } \\
\text { familias y la comunidad en las escuelas. }\end{array}$ \\
\hline
\end{tabular}

Fuente. Elaboración propia.

\section{Resultados}

Los resultados obtenidos fueron clasificados de acuerdo a las meta-categorías obtenidas en el análisis de la información. En relación al presente eje temático estas fueron: visión directiva, actividades de participación y condicionantes del contexto.

\subsection{Visión directiva}

Indagamos en las visiones que tienen los directores con respecto a la participación y las dificultades detectadas por ellos en relación a su promoción. De ello exponemos:

\subsubsection{Participación}

Todos los directores entienden que la participación de las familias y la comunidad es un proceso fundamental en la vida de las escuelas. Afirman que los padres son parte importante del proceso educativo de sus hijos y concuerdan en que la participación permite mejorar su educación. 
Categóricamente afirman que los padres son los primeros y más importantes educadores de sus hijos. Al respecto uno de ellos señaló: “...los padres son una parte de la comunidad escolar que todo establecimiento debe privilegiar para que se aboquen a una misma tarea, obtener buenos aprendizajes de los estudiantes..."

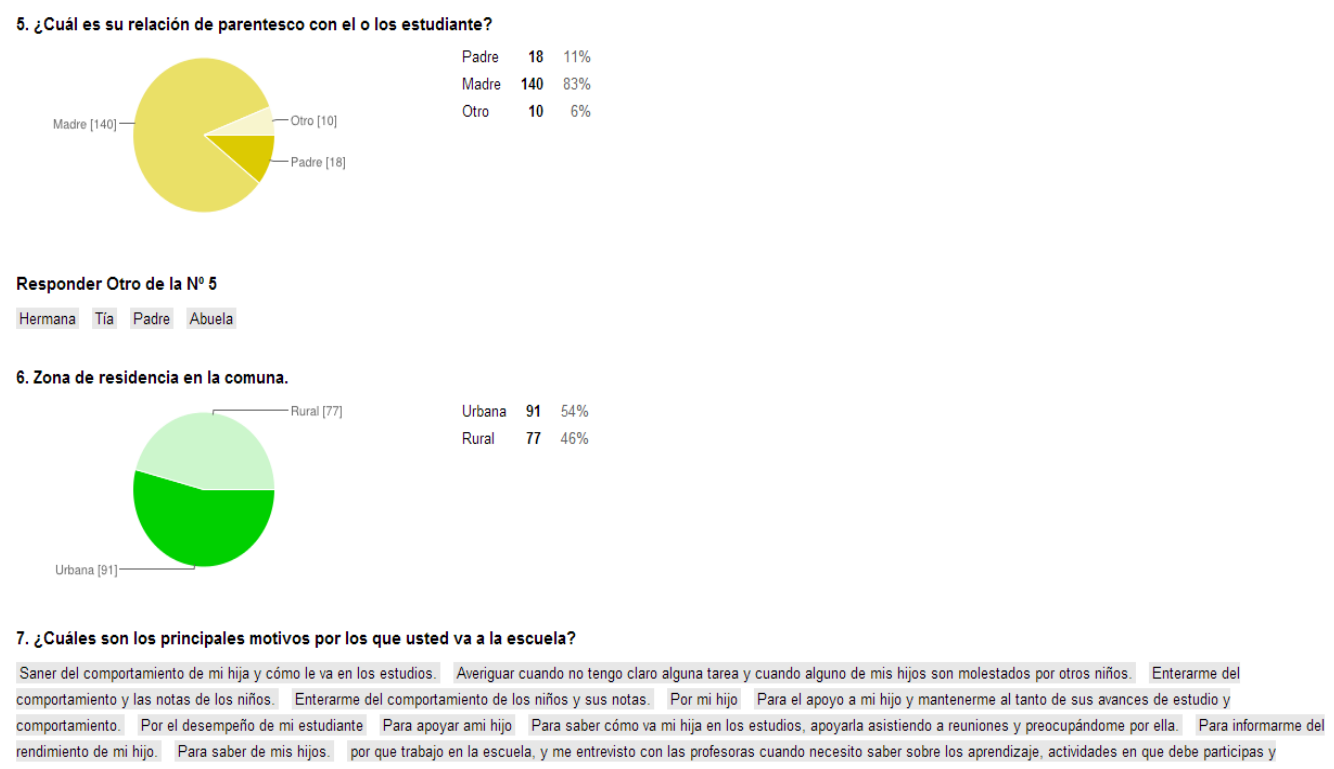

Figura 7. Tabulación información cuestionario de padres

Fuente: Elaboración propia.

Concuerdan en que su rol participativo debe reflejarse en una mayor implicación, donde las familias manifiesten sus opiniones sobre la vida institucional, el quehacer educativo y ser considerados en la toma decisiones. Conciertan en que la participación no debe circunscribirse únicamente a entregar información o asistencia pasiva a las convocatorias de la escuela. La siguiente afirmación lo expresa: "La participación no solo tiene que ver con la entrega de información, va más allá. Por ejemplo si vas a hacer la reformulación de tu Proyecto Educativo Institucional debes tomar en consideración lo que ellos puedan aportar".

En relación a la participación de la comunidad, existe consenso en que el entono social es relevante como promotor del mejoramiento educativo (Flecha, 2009; Salimbeni, 2011; Silva, 2008). Al menos ocho directores enfatizan su importancia. Siente que esta relación debe desarrollarse bidireccionalmente y que las escuelas deben promover el acercamiento con su medio. Sin embargo, desde el punto de vista personal solo cinco de los directores mantiene una participación permanente en alguna instancia de la vida social de sus comunidades. Los otros lo hacen movilizados por las obligaciones del cargo. Algunas declaraciones al respecto dicen: "Yo participo del Rotary Club, que es mi instancia más formal. Trato de estar siempre visible en lugares importantes..."; "No, a título personal no participo en la comunidad..."

Esto evidencia que la reciprocidad de colaboración manifestada por los directivos no se reflejaría en su justa dimensión. Parece ser que por un lado sí se presentan niveles adecuados de participación con los agentes comunitario pero la respuesta colaborativa de los directores parece ser débil. 


\subsubsection{Dificultades}

A pesar de que existe una alta valoración de la participación, queda de manifiesto que no está exenta de dificultades:

\section{Niveles de participación de las famílias}

Son conscientes de que es necesario seguir abriendo espacios de participación, incrementando el apoyo formativo hacia los padres. Aspiran a fortalecer la autonomía para que sean las familias quienes asuman un rol más activo en la escuela partiendo de sus propias necesidades.

\section{Compromiso de los padres para con la educación de sus hijos}

Cinco de los diez directores cree que las escuelas no deberían preocuparse por promover la participación. Esto debe ser un acto natural y espontáneo de los propios padres. La mayoría de las madres -participantes del grupo de discusión- también coinciden en que no tendría por qué ser un tema de preocupación de la escuela Manifiestan que son los padres los que no están cumpliendo sus obligaciones. Aquello lo grafican de la siguiente manera: "A la mayoría de los apoderados no les interesa nada, porque se ha intentado de todo y la verdad es que no hay llegada".

Todos los directores coinciden en que las madres son quienes asumen las mayores responsabilidades vinculadas a los compromisos educativos de los hijos y mantienen el vínculo con las escuelas, independientemente si tienen o no una actividad laboral fuera de casa. Los papás preferentemente se abocan a trabajar. Parece ser que la mayoría de los papás se desliga de esta responsabilidad, al menos desde su presencia directa en la escuela. Uno de los directores afirma: "El hombre se desliga de su rol de padre responsable de la parte educacional, él solamente disfruta del término del año escolar, de la entrega de un certificado, pero no está en el del proceso..."

Antecedente complementario de esta afirmación es el resultado de la participación de género en el cuestionario aplicado a los padres. De un total de 150 personas que declararon su género, 135 fueron mujeres (90\%). Otro antecedente es la total presencia de mujeres participantes en el grupo de discusión, quienes tras sus relatos igualmente ratificaron esta realidad.

\section{Visión sobre la misión de las escuelas que poseen las familias}

La totalidad de los directores aseveran que las familias aún asumen que la escuela es quien tiene la mayor potestad sobre la educación de los estudiantes, al menos en términos cognitivos. Sienten que los padres -en general- aceptan pasivamente lo que las escuelas hacen y proponen. Por esto mismo creen que no se reconocen como agentes educadores, no se sienten valorados y menos incorporados al sistema. Sin embargo, ellos mismos declaran que aquello puede producirse debido a que las mismas dinámicas escolares -y la gestión directiva en particular- pueden provocar esto. Un director reconoce lo anterior declarando que: "Yo percibo que no siempre los apoderados consideran que su participación es relevante o que son tomados en cuenta".

Igualmente, más de la mitad concuerdan en que los padres casi no se inmiscuyen en los lineamientos pedagógicos y en los contenidos del Proyecto Educativo Institucional. Participar en actividades pedagógicas no es una prioridad. Siempre serán las actividades festivas y celebraciones las que acaparen mayor interés. Esto lo refirma este fragmento: "Los apoderados por lo general vienen poco por cosas pedagógicas", lo que se refleja en 
el bajo interés que demuestran por las actividades que puedan ayudarles a fortalecer su rol educativo. Al respecto dicen: "Se involucran más con actividades como aniversario del colegio, Fiestas Patrias, licenciaturas". Su rol es fundamentalmente receptivo y muchas veces pasivo en aspectos que tendrían que ser de su interés.

Los resultados del cuestionario de padres ratifican lo anterior. Ante la pregunta: Si usted participa en la escuela ¿En qué actividades lo hace?, las respuestas mayoritarias apuntaron a aquellas de corte recreativo, deportivas, celebraciones y actos. Un $44 \%$ de los padres dijo asistir con frecuencia a los eventos artísticos culturales, licenciaturas, actos del Día de la Madre, Día del Alumno, Día del Profesor, entre otros. En menor proporción (14\%) lo hacen en convivencias y colaborando con trabajo en actividades de los cursos o el Centro General de Padres. Un grupo ínfimo declara participar en actividades de las bibliotecas, talleres, acompañando a los niños en viajes o apoyando alguna actividad extraescolar. Un 7\% declara no participar ni asistir a nada.

La información obtenida a través de las observaciones no participante dejaron ver que la asistencia a las reuniones es baja, evidenciándose un promedio de asistencia inferior a la media.

\subsection{Actividades de participación}

De acuerdo a su origen, orientaciones y beneficiarios pudimos clasificar las actividades de participación en tres ámbitos, cada una con diferentes modalidades, tal como lo muestra la tabla 4 .

Tabla 4. Clasificación de actividades de participación en las escuelas de Panguipulli

\begin{tabular}{|c|c|c|}
\hline ÁmBITOS & BENEFICIARIOS & MODALIDADES \\
\hline $\begin{array}{l}\text { Escuela - Familias } \\
\text { - Comunidad }\end{array}$ & Familias - Comunidad & $\begin{array}{l}\text { Formativas (charlas y talleres) - Reuniones - } \\
\text { Celebraciones de efemérides - Festividades y } \\
\text { Ceremonias - Artístico/ Deportivas - Solidarias }\end{array}$ \\
\hline Familias - Escuela & Escuela-Alumnos & $\begin{array}{l}\text { Colaboración con trabajo - Apoyo a la enseñanza - } \\
\text { Apoyo económico }\end{array}$ \\
\hline $\begin{array}{l}\text { Comunidad - } \\
\text { Escuela }\end{array}$ & $\begin{array}{l}\text { Escuela - Alumnos - } \\
\text { Familias }\end{array}$ & $\begin{array}{l}\text { Apoyo educativo - Mejoramiento infraestructura - } \\
\text { Asistencialidad }\end{array}$ \\
\hline
\end{tabular}

Fuente: Elaboración propia.

\subsubsection{Actividades Escuela - Familia - Comunidad}

Son impulsadas por las escuelas a objeto de dotar a los padres de conocimientos, habilidad, valores o actitudes que vayan en beneficio del fortalecimiento de los procesos educativos familiares y del bienestar de las mismas. Se espera que redunden en el mejoramiento de los aprendizajes de los estudiantes.

Aun cuando los directores le asignan gran validez, todos coinciden en afirmar que en sus escuelas han realizado talleres para padres con variadas temáticas (informática, deportivas, artesanales, otras) y que ellos no se interesan por asistir. Esto lo confirman también las apoderadas asistentes al grupo de discusión: “...nuestra directora puso un taller de aeróbica y de cocina para los papás el año pasado y hubo casi nula participación, tuvo que eliminarlo..."

En relación a las reuniones de padres existe descontento con las dinámicas y temáticas de las mismas, lo que al parecer constituye una causas en la baja asistencia. Uno de los directivos señaló: "Uno de los argumentos que se dan los apoderados es que no vienen a las reuniones porque son muy aburridas", esto a raíz de que por muchos años el centro 
de interés han sido los temas económicos y organización de actividades recreativas y celebraciones. Todas las madres participantes del grupo de discusión estuvieron de acuerdo en que: "No queremos ir porque nos agobian las reuniones, a lo mejor se pide mucho, que la cuota, que el beneficio, que esto, que lo otro".

Sin embargo, la mayoría de los directores han comenzado a impulsar cambios estructurales, focalizando la intención en aspectos pedagógicos y formativos por sobre los económicos y festivos tan tradicionalmente arraigado.

Pudimos establecer cuatro modalidades de reuniones que realizan los directores, en las que transversalmente se presentan tres enfoques distintos (figura 8).

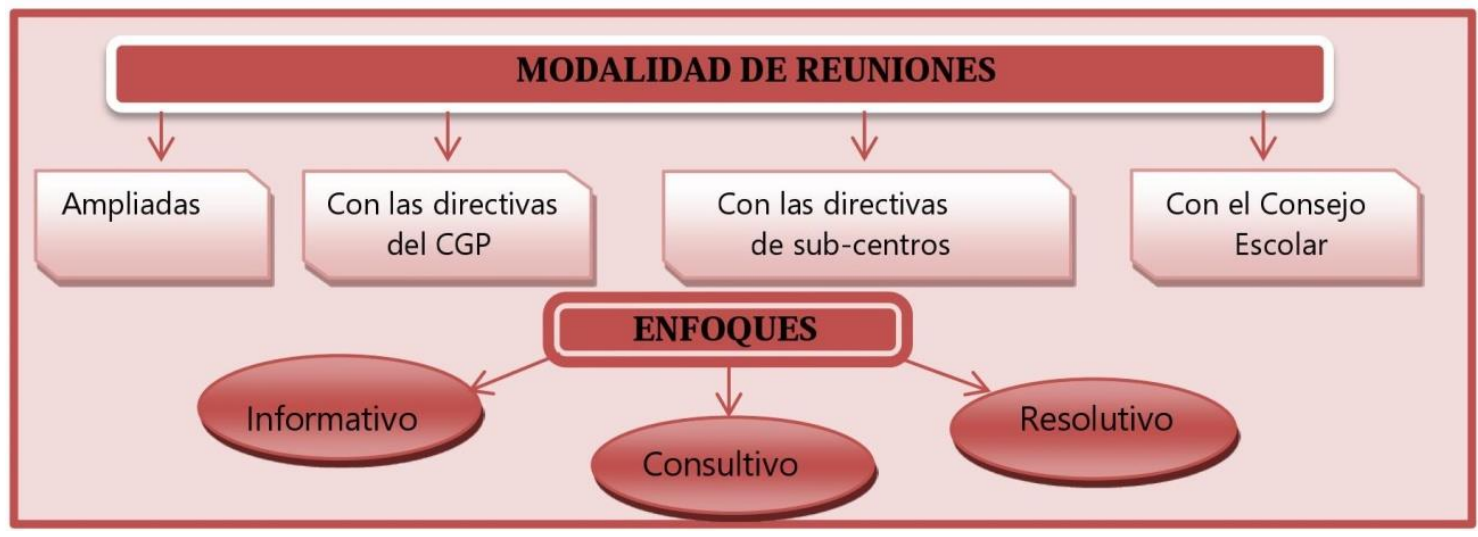

Figura 8. Modalidades y enfoques de reuniones de directores con padres y comunidades Fuente: Elaboración propia.

En cada modalidad, dependiendo del estilo directivo, se refleja una mayor o menor presencia de alguno de los tres enfoques, aunque el predominio es el informativo. En menor grado el consultivo y en instancias muy reducidas las resolutivas.

Se estableció que las reuniones ampliadas de padres son dirigidas por los directores y se realizan entre dos y cuatro al año. Son instancias principalmente informativas sobre la situación actual y futura de las escuelas y rendición de cuentas sobre ingresos y egresos de dinero. Un testimonio de aquello es: "Nosotros acá hicimos la cuenta pública, con un recuento generalizado de todas las actividades del año anterior y rendición de dineros que ingresan y salen tanto del nivel colegio como del Centro de Padres".

Las reuniones con las directivas del Centro de Padres son dirigidas por el director y no presentan regularidad de realización. Se convocan principalmente ante situaciones importantes por resolver. Es una instancia informativa, consultiva y resolutiva, principalmente en temas de colaboración en servicios e inversiones de recursos, como por ejemplo: determinar algún beneficio, conformar comisiones de trabajo, definir la utilización de dineros, etc. Por estar compuesta por pocas personas es una instancia de diálogo más abierto y participativa como para readecuar documentos oficiales (Proyecto Educativos Institucional o Manuales de Convivencia), situación que a nuestro entender se presenta restrictiva y escasamente representativa.

En cuatro a las reuniones con las directivas de los sub-centros son dirigidas por los integrantes de la directiva del Centro de Padres, aunque también asiste el director o un representante de él. Son convocadas entre tres o cuatro veces al año. El enfoque predominante es el informativo/consultivo, con una leve inclinación resolutiva sobre 
temas propuestos por la misma directiva o sugeridos por los directores. De ello dan cuenta que: "La reformulación de estos instrumentos te obliga a compartir y dar participación a los estamentos, pero ya de forma más interna...el rol de los padres se observa en decisiones que puedan ser tomadas por ellos y sus opiniones son consideradas, pero tiene que ver con las buenas ideas. Cuando un apoderado te da una sugerencia que es pertinente tú la tomas, pero no al contrario".

Las reuniones con el Consejo Escolar son dirigidas por el director y participa un representante de los padres, de los docentes, de los asistentes de la educación y del Sostenedor. Dependiendo del estilo de dirección, en algunos casos se incluyen a representantes de los alumnos, instancias comunitarias o redes de apoyo. Es una actividad normada legislativamente que se debe realizar cuatro veces al año. La legislación le asigna un carácter informativo/consultivo y no resolutivo, a menos que el director en acuerdo con el Sostenedor resuelva lo contrario. En la comuna esto no se evidenció.

Otra modalidad de actividades en este ámbito son las conmemoraciones de efemérides, que resaltan acontecimientos del calendario nacional y de cada establecimiento. Son de carácter abierto y público y en todos los casos está presente la figura colaborativa y participativa de los padres y la comunidad, ya sea como espectadores o trabajando en la preparación de alimentos u ornamentación de espacios. Uno de los directores comenta: "Para las Fiestas Patrias se hace un acto con comidas típicas y juegos tradicionales en la que participan los padres como espectadores y trabajando".

También estas actividades se concretan a través de actos conmemorativos y ceremonias oficiales como el Día de los Pueblos Originarios, el Día del Carabinero, el Día del Profesor, Día de la Madre, del Padre y celebraciones religiosas en escuelas con esa orientación.

Las festividades y ceremonias son otras actividades, que nacen de iniciativas internas. Entre ellas destacan las celebraciones de aniversarios, despedidas de curso, licenciaturas de kínder y octavos años y finalizaciones de semestres académicos, donde algunos padres participan colaborando con trabajo y aportando con donaciones en alimentos o dinero.

Con similares características encontramos actividades artístico/deportivas, donde los padres se involucran colaborando con trabajo o apoyando a sus hijos para su participación. Entre las más relevantes destacan encuentros deportivos inter-escolares, galas artísticas, exposiciones, encuentros de música, muestras gastronómicas.

En menor grado y de manera aislada se desarrollan actividades solidarias. La más masiva es la Teletón ${ }^{1}$, campaña nacional a la que se suman todas las escuelas de la comuna y donde se involucran directamente todos los agentes educativos.

El carácter distendido de las actividades de este ámbito las transforma en las más representativas de participación. La reflexión de un padre nos aproxima a esto: "En nuestra escuela participamos mirando los actos y otras actividades".

Los resultados obtenidos denotan una ausencia significativa de actividades centradas en aspectos académicos y formativos para padres, ámbitos en que los directores deben

${ }^{1}$ Programa de televisión de 27 horas ininterrumpidas de duración, producido y transmitido por todas las cadenas televisivas. Los fondos recaudados son utilizados en la construcción y mantención de los Institutos de Rehabilitación Infantil para el tratamiento de niños con discapacidades motrices. 
prestar atención preferencial. Finalmente es dable revelar que la mayoría de estas actividades son gestadas de manera unilateral por las escuelas, ya sea porque están institucionalizadas o por iniciativa de los Consejos de Profesores, con escasa vinculación de los padres en su planificación.

\subsubsection{Actividades Familia - Escuela}

Se entienden como aquellas focalizadas en la colaboración de los padres para fortalecer las actividades de enseñanza para sus hijos y satisfacer algunas necesidades institucionales. Resultado de las indagaciones se establecieron tres modalidades (figura $9)$.

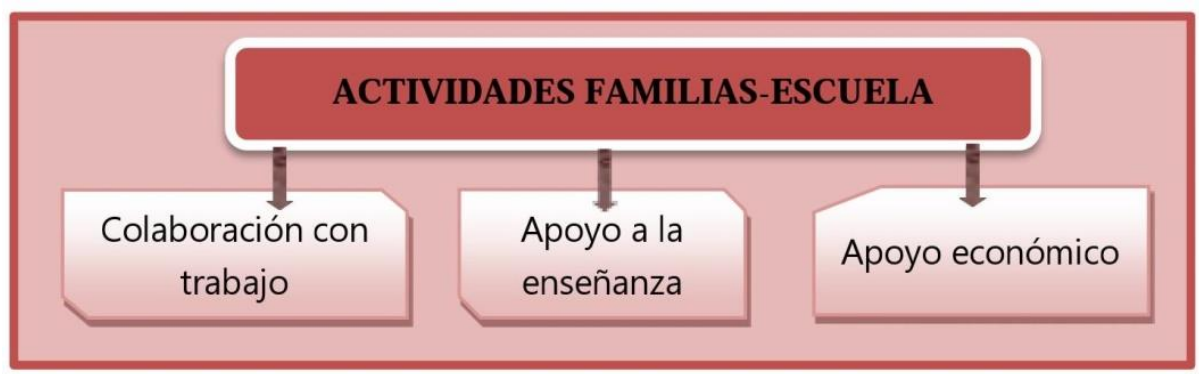

Figura 9. Actividades colaborativas de las familias en las escuelas Fuente: Elaboración propia.

La colaboración con trabajo es la actividad más generalizada y se concreta con la participación de los padres que forman parte de las directivas de los cursos o del Centro de Padres, quienes mayormente marcan presencia colaborando en la organización y desarrollo de actividades. Este tipo de colaboración ha ido en paulatina retirada gracias a la inyección de recursos económicos que las escuelas perciben a través de la Ley de Subvención Escolar Preferencial con las que pueden financiar algunas iniciativas que antes eran cubiertas por las familias.

El apoyo a la enseñanza prácticamente no se visualiza. En casos muy aislados algunos padres se involucran en colaborar en alguna actividad esporádica como monitor en un taller o participando en alguna unidad didáctica de asignatura. Ello refleja el distanciamiento de las familias con respecto a los exiguos espacios de participación de colaboración pedagógica.

Con respecto al apoyo económico, es una actividad que al igual que con el trabajo se observa en retirada, aunque aún vigente, ya que los recursos que reciben las escuelas a través de la ley antes mencionada no contempla el financiamiento de algunas actividades o inversiones para las escuelas.

\subsubsection{Actividades Comunidad-Escuela}

Este ámbito se presenta con un nivel de colaboración muy significativo, principalmente por el compromiso en la comuna de instituciones privadas y algunas organizaciones comunitarias. Éstas se resuelven principalmente en tres tipos (figura 10).

Respecto del apoyo educativo, los directores destacan el aporte desinteresado de varias instituciones privadas. Éstas han aportado a las escuelas con implementación en recursos materiales, infraestructura e iniciativas de fortalecimiento, tanto en lo educativo como en la proyección futura de los alumnos. En este sentido, han sido muy escasos los esfuerzos 
de gestión que han realizado al menos la mitad de los directores, porque las propias instituciones se han acercado a las escuelas propiciando esta relación. Dicho suceso bien lo relata uno de los directores: “...yo casi no me he movido de mi escritorio para conseguir cosas, ellos han llegado aquí...”. Destacan de esto, proyectos de lecturas y bibliotecas abiertas a la comunidad, programas de apoyo educativo en lenguaje y matemáticas y profesores itinerantes de música para alumnos de primeros años.

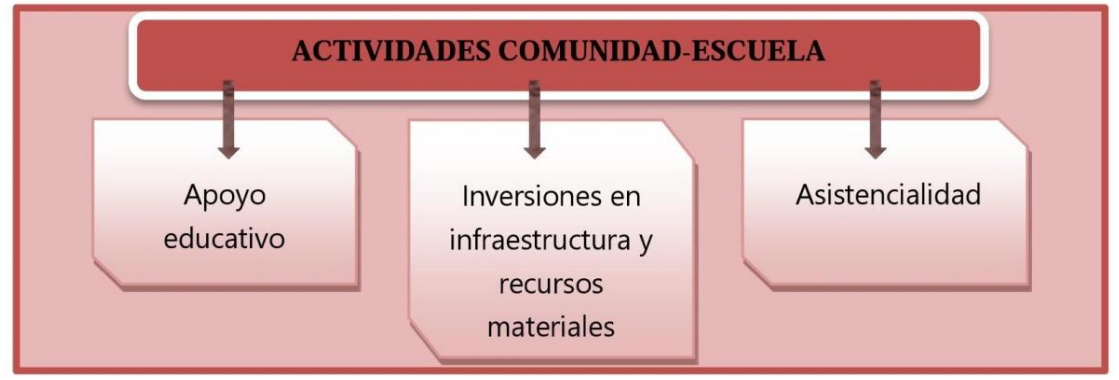

Figura 10. Áreas de actividades de participación de la comunidad en las escuelas en Panguipulli

Fuente: Elaboración propia.

Agentes de la comunidad igualmente colaboran con las escuelas con diversas donaciones para eventos, actividades o beneficios para recaudar fondos. Algunos de ellos son comerciantes locales y microempresarios. Uno de los directores nos confirma esto ejemplificando que: "Con la Cámara de Comercio y algunos dueños de locales comerciales tenemos algún tipo de relación. Cuando hay que realizar alguna salida con los chicos algún empresario o comerciante nos hace llegar algún recurso económico para palear los gastos...”.

En relación a la colaboración en el ámbito asistencial, estas actividades se desarrollan principalmente en coordinación con Carabineros de Chile y los Centros de Salud cercanos. Son acciones que se encuentran institucionalizadas desde hace muchos años, aunque es más notoria su presencia en las escuelas rurales.

\subsection{Condicionantes del contexto}

La comuna de Panguipulli presenta una diversidad de elementos que tienden a facilitar los procesos de promoción y otros que dificultan su concreción. Según todos los directores, el principal facilitador es la buena disposición que tienen los profesores y asistentes de la educación, evidenciado en el trabajo que realizan fuera del horario laboral. Testimonios como este ratifican esta idea: “...los colegas que trabajan más allá del tiempo, colegas que se entregan un $100 \%$, hay mucho apoyo”.

Un segundo elemento es la disponibilidad de recursos económicos de las escuelas, que les permite financiar algunos gastos operacionales y logísticos como el transporte para los padres a algunas reuniones o algún servicio de alimentación para quienes viven lejos.

Contrario a esto, la mayoría de los directores cree que son dos los mayores condicionantes que dificultan la participación de padres: La falta de compromiso de las familias y la débil relación de confianza entre las escuelas y familias.

La figura 11 detalla claramente sus causas, las que subyacentes bajo las apreciaciones de los directores, docentes, asistentes de la educación y los propios padres. Mitigar esta 
situación implica que los directores deban considerar algunas condiciones importantes a este respecto. Por ejemplo, al ser consultados los padres en el cuestionario sobre: ¿Bajo qué condiciones aumentaría su participación en la escuela?, manifestaron que podrían aumentarla si contaran con más tiempo (40\%), lo que se condice con los obstáculos que ellos y los directores han manifestado. La segunda condición, si tuviera más información de las reuniones y actividades (19\%), lo que podría ser evidencia de una débil comunicación. Un número menor cree que aumentaría su participación si proporcionaran transporte $(10 \%)$, ya que la distancia y dispersión geográfica, sumado a la falta de recursos económicos, les dificulta asistir con regularidad a las escuelas; finalmente, igual número de ellos requiere que los directores sean más asequibles, cordiales y receptivos $(10 \%)$. En menor grado declaran que aumentarían su participación si se les respetara su condición social, económica o educativa ( $8 \%$ ) lo que parece demostrar que los padres sienten un cierto grado de discriminación por parte de los directores.

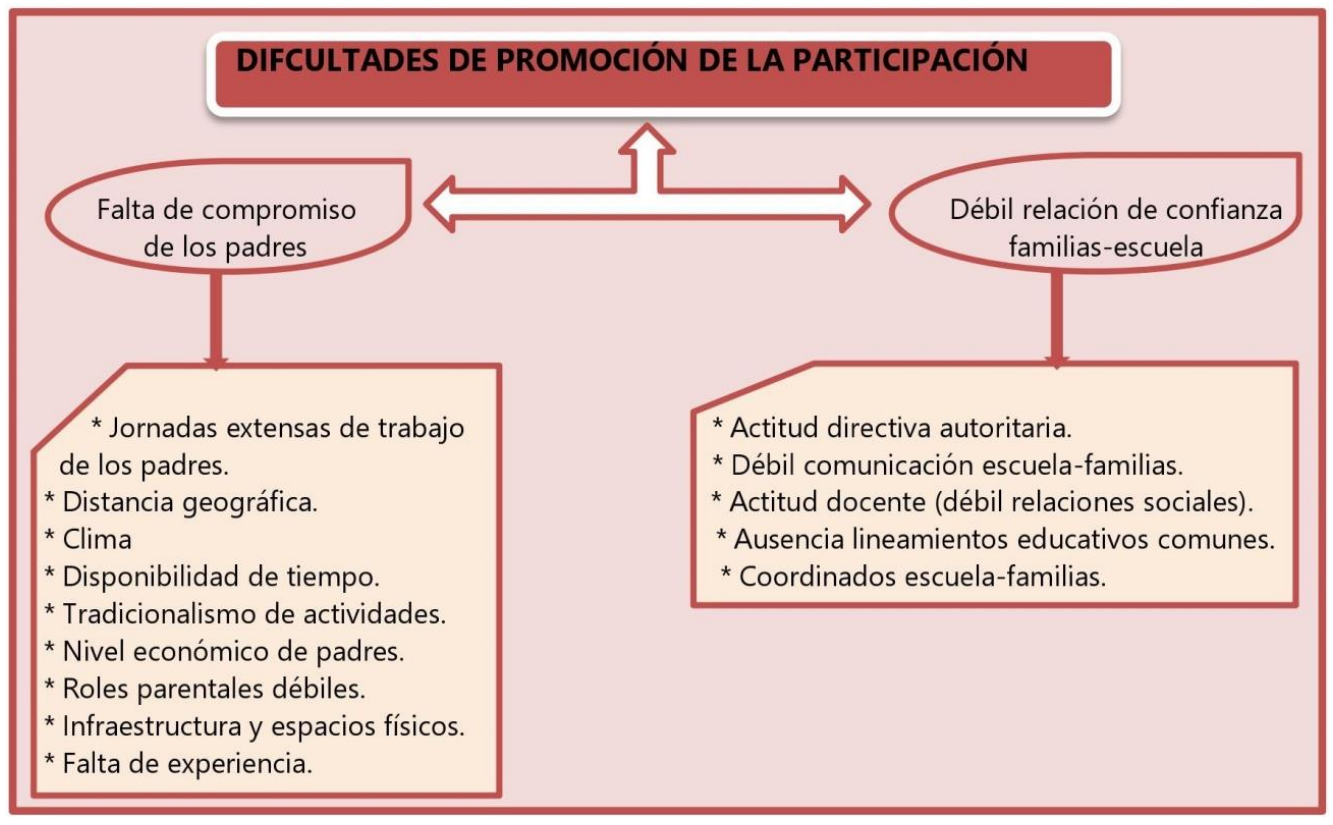

Figura 11.Principales dificultades de promoción de la participación en Panguipulli Fuente: Elaboración propia.

Es interesante rescatar la siguiente reflexión de un padre que a nuestro parecer representa el sentir de muchos de ellos: "No he tenido mayores dificultades con mi participación en la escuela, pero en algunos casos éstas se hacen más por obligación que por gusto".

Evidentemente gran parte de los padres actúa de manera obligada más que por una motivación intrínseca, condición preocupante a la que se debe prestar atención si se pretende implicar a las familias como aliados en los procesos de mejora.

Por otra parte, todos los directores señalan que gran parte de sus prácticas directivas las orientan en promover la participación. Sin embargo, a pesar de ser un tema valorado condicionan ciertos límites a los padres en cuanto a su injerencia en algunos temas y decisiones. Son enfáticos en señalar que éstos deben respetar los límites establecidos y no inmiscuirse en áreas que no les corresponde, principalmente lo técnico pedagógico. 
Dicen, "El apoderado no pueden venir a cada rato a la escuela...el apoderado participa en el Centro de Padres, en el Consejo Escolar o en otra instancia, pero no existe otra”.

Todos muestran una posición determinante en relación a aquello, siendo quienes ponen los límites de participación y conocen con claridad hasta qué punto deben llegar los padres. Las familias parece no tenerlo del todo claro, ya que varias madres presentes en el grupo de discusión manifestaron sus dudas al respecto señalando que: “ ¿Hasta dónde están mis límites como presidenta de Centro de Padres y cuál es el límite que tiene la directora conmigo? Yo hasta el momento lo desconozco. Quizás eso falta, que los directores dejen más establecido esos límites para uno lo tenga claro”.

\section{Discusión y conclusiones}

Los procesos de participación en las escuelas son complejos y el papel de los directores como líderes educativos es fundamental en su promoción, quienes deben hacer verbo convicciones conceptuales tan importantes como el sentido compartido del acto de educar, de comunidad, de pedagogía compartida, compromiso y responsabilidad, tal como lo afirman destacados autores en el área (Flecha, 2006; Kidder, 2013; Penalva, 2008; Salimbeni, 2011; Tierney, 2002; Torío, 2004), solo así lo educativo dejará de reducirse al espacio escolar, permitiendo a las escuelas continuar con la tarea educativa iniciada en las familias y la comunidad.

Valoramos la importancia de la participación en la mejora de los procesos educativos y la formación integral de los estudiantes, por cuanto la familia es el agente más importante en la educación de los niños. Así, la escuela tiene el deber de asociase para fortalecer su cometido, desarrollando acciones en comunión que impriman un sentido educativo al acto participativo, generando prácticas y estrategias que movilicen sentidamente a los agentes involucrados, misión que deben desarrollar fuertemente los directores.

Ellos ser capaces de reconocer las potencialidades educativas inherentes de los agentes y el aporte que pueden realizar al proceso educativo. Continuar con una idea estrecha de la educación retrotrae lo educativo solo al conocimiento disciplinar y la concepción de participación continuará en la superficialidad funcionalista.

Los actuales modos ver y operacionalizar la participación hacen urgente que los directores promuevan una cultura de participación pedagógica, que fortalezca una implicación con orientación formativa, más allá de lo estrictamente curricular, ya que tal como reconoce De la Guardia y Romero (2010) "la participación de las familias se desarrolla en actividades periféricas, que nada tienen que ver con los aspectos nucleares de la vida del centro" (pp.23). Por ello, una participación pedagógica dotará cambio y sentido a la gestión directiva a través de actos formadores, entendidos como prácticas de gestión vinculadas a un sentido educativo, actos que deben trascender la sola ejecución burocrático-administrativa del desempeño, enfoque compartido por Murillo (2006) quien afirma que "De esta forma, se refuerza la idea de que la dirección tiene como máxima prioridad las personas, no los papeles ni las tareas. El director o directora para el cambio han de centrarse en el desarrollo de las personas que conforman la escuela" (pp. 21). Aquello marcará la diferencia entre un administrador educacional y un director "educador".

La ausencia de actividades formativas para padres es una dimensión con débil presencia en las escuelas. No se han agotado las estratégicas para su instalación y las políticas 
educativas no solidarizan en ello, por la presión de resultados académicos que se les exige a las escuelas. En esto, los Centros de Padres podrían transformarse en protagonistas impulsores de iniciativas de autoformación, haciendo propios los deberes y derechos asignados en los estatutos fundacionales y de los cuales no se han hecho cargo. He aquí un desafío concreto y realizable.

Teóricamente los directores están empapados de los principios orientadores y benéficos de la participación y realizan esfuerzos por promoverla, aunque no son conscientes que sus prácticas son restrictivas y tradicionalistas. Éstas no sobrepasan los niveles informativo y consultivo, privilegiándose la asistencialidad de los padres a las escuelas. Cabe preguntarse entonces cipor qué si lo padres son tan importantes en la educación de los niños -como afirman los directores- las escuelas limitan los niveles de participación a la recepción de información y pasividad en sus actividades? Esta paradoja exige urgente redirección y los directores deben liderar estos procesos.

Indefectiblemente se mantiene la presencia de confusos canales de comunicación que debilitan los lasos de confianza y sostienen incertidumbres relacionales. Es ventajoso socializar y conciliar principios formativos y orientaciones educativas entre las familias, las escuelas y la comunidad, debiendo ser los directores sus promotores.

Por ello es conveniente avanzar hacia una participación más autónoma, que permita a las familias ser consideradas efectivamente en la toma decisiones y conducirse libremente en lo que les corresponda respecto de la vida institucional y el quehacer educativo en las escuelas.

Sostenemos que las actuales circunstancias que rodean a los entornos familiares y las dinámicas escolares no sostienen el actual paradigma. Sabemos que es necesaria la presencia física y el acompañamiento de las familias en las escuelas, pero de igual manera -o más importante- es las forma en cómo los padres se involucran, participan y se comprometen conscientemente con la educación de sus hijos desde el hogar. Esto amerita ser repensado y plantearnos, tal como afirma Kidder (2013), otros modos de hacer, promoviendo prácticas que fortalezcan la participación pedagógica en el propio hogar, desplegando los esfuerzos en potenciar el rol educativo de las familias en coordinación y apoyo con la escuela.

Son casi inexistentes los estudios que abarcan la participación comunitaria de los directores. Nuestro estudio concluyó que ésta se presenta poco visible. Implicarse es una decisión personal que no todos comparten, por cuanto lo asumen como una responsabilidad y deber del cargo. Será oportuno, a razón de la bilateralidad del sentido social de la educación, que los directivos deban involucrarse más activamente en la vida de sus comunidades, aportando con sus conocimientos y liderazgo al desarrollo social de las mismas, transformándose en agentes socioeducativos referenciales. Su ausencia en la escena social local desaprovecha el potencial aporte que pudieran realizar, toda vez que el liderazgo directivo debiera de estar al servicio del desarrollo social.

La participación de los agentes educativos externos, tal como lo plantea el movimiento de comunidades de aprendizaje (Flecha, 2006) debe mantenerse con activa presencia colaborativa, destacándose en ellos un compromiso sustancial con la mejora de la educación en la comuna. Sin desmedro de esto, siempre será necesario que los directivos se movilicen en su promoción. 
El efectivo desempeño directivo como promotor de la participación se encuentra condicionado a una serie elementos contextuales que dificulta su concreción y que los directores deben atender: situación laboral y disponibilidad de tiempo de los padres, distancia geográfica, desinterés y escasa motivación por asistir a las escuelas, divergencia en relación al rol educador de las escuelas, el clima y los recursos económicos de las familias.

En suma, la dirección escolar en Panguipulli se enfrenta a una importante oquedad. Hoy por hoy, cambiar la trayectoria del hacer tradicionalista, superar las diferencias y unificar los criterios de acción educativa con las familias son desafíos prioritarios de la gestión directiva, los que podrán ser resuelto en la medida que los directores asuman una posición transformadora frente al acto educativo y se permitan romper con los esquemas tradicionales e incrementen los niveles de participación, tan como lo recomiendan Antúnez (2000), Flamey y colaboradores (2005), Flecha (2006), Kidder (2013) y Silambeni (2011).

\section{Agradecimientos}

Los autores desean agradecer a CONICYT Chile por el apoyo financiero de Beca de Postgrado al primer autor, gracias a la cual se puedo llevar a cabo el presente estudio. De igual manera a Universidad de Barcelona, España por las facilidades y beneficios entregados.

\section{Referencias}

Antúnez, S. (2000). La acción directiva en las instituciones escolares. Análisis y propuestas. Barcelona: Editorial Horsori.

Aylwin, M. (2013). Prólogo de Mariana Aylwin. En M. Saracostti (Coord.), Familia-escuelacomunidad. Una alianza necesaria para un modelo de intervención biopsicosocial positivo (pp.1920). Santiago: Editorial Universitaria.

Ball, S. J. (1994). La micropolítica de la escuela. Hacia una teoría de la organización escolar. Barcelona: Paidós.

Contreras, L. (2011). Análisis de las reformas educacionales en Chile y América Latina. Recuperado de http://goo.gl/KjzMOa

De la Guardia, R. M. y Santana, F. (2010). Alternativas de mejora de la participación educativa de las familias como instrumento para la calidad educativa. Revista Iberoamerica sobre Calidad, Eficacia y Cambio en Educación, 8(3), 56-67.

Flamey, G., Pérez, L. M., Sirvents, S., Guzmán, A., Hojman, V., Anaís, M. J. y Calderón, P. (2005). Participación de los centros de padres en educación. Santiago: Contempo Gráfica.

Flecha, R. (2006). La participación de las familias en las comunidades de aprendizaje. En A. García (Coord.), La participación de las familias en la vida escolar: acciones y estrategias (pp. 5967). Madrid. Estilo Estugraf Impresores.

Fundación Chile. (2006). Perfiles de competencias directivas, docentes y profesionales de apoyo. Programa de educación, gestión escolar. Santiago: Fundación Chile.

Gairín, J. (2003). Formación de directores y directoras de centros educativos. Gestión Organizativa 2. Barcelona: Universidad de Barcelona Virtual. 
Hernández, R., Fernández, C. y Baptista, P. (2006). Metodología de la investigación. México: Mc Graw Hill.

Kidder, A. (2013). El papel clave de las familias en educación. Recuperado de http://goo.gl/E7B3ut

Maykuy, P. y Morehouse, R. (1998). Beginning qualitative reserch. A philosophic and practical guide. Londres: The Flamer Press.

MECD. (2004). Evolución del sistema educativo español. Madrid: MECD/CIDE.

Morillo, E. (2002). Reformas educativas en el Perú del siglo XX. Recuperado de http://rieoei.org/deloslectores/233Morillo.PDF

Murillo, J. (2006). Una dirección para el cambio: del liderazgo transformacional al liderazgo distribuido. REICE. Revista Iberoamericana sobre Calidad, Eficacia y Cambio en Educación, $4(4), 11-24$

OCDE. (2012a). PISA 2012 Results in focus. What 15-year-olds know and what they can do with what they know. París: OECD Publishing.

OCDE. (2012b). Avances en las reformas de la educación básica en México: una Perspectiva de la OCDE. París: OECD Publishing.

Penalva, J. (2008). Carta de un maestro. Sobre la educación en la sociedad y en la escuela actual. Madrid: Biblioteca Nueva.

Salimbeni, O. (2011). Escuela y comunidad. Participación comunitaria en el sistema escolar. Tendencias Pedagógicas, 17, 19-32.

Sandín, M. P. (2010). La investigación cualitativa en educación. Fundamentos y tradiciones. Madrid: McGraw Hill.

Santizo, C. (2009). Guía del Director y CEPS para promover la participación social en los procesos de decisión de las escuelas. Recuperado de http://goo.gl/OVgMO4

Silva, P. (2008). La inspección escolar en Cataluña. Un estudio de casos (Tesis Doctoral). Universidad de Barcelona, Barcelona.

Tejada, J. (2000). La educación en el marco de una sociedad global: Algunos principios y nuevas exigencias. Profesorado, Revista de Currículum y Formación del Profesorado, 4(1), 1-13.

Tierney, W. (2002). Parents and families in precollege preparation: the lack of connection between research and practice. Educational Policy, 16(4), 588-606. doi:10.1177/0895904802016004007

Torres, R. (2001). Participación ciudadana y educación. Una mirada amplia y 20 experiencias en América Latina. Recuperado de http://goo.gl/ssaaBE

\section{Breve CV de los autores}

\section{Claudio Barrientos Piñeiro}

Profesor de Educación Primaria con experiencia en docencia de aula, jefaturas técnicas académicas y dirección de escuelas básicas en Chile. Formación en académica en los ámbitos de la didáctica, formación del profesorado y evaluación educacional. Máster en Dirección y Gestión de centros Educativos y Máster en Investigación Educativa por la Universidad de Barcelona. Doctor en Ciencias de la Educación por la Universidad de Barcelona. Publicaciones realizadas en el ámbito de la evaluación educativa y un libro biográfico narrativo. Email: clabapineiro@gmail.com 


\section{Patricia Silva García}

Maestra de Educación Primaria, Licenciada en Sociología, Máster en Desarrollo Educativo con especialidad en Organización y Gestión de Centros educativos, Máster en Dirección y Gestión de Centros Educativos. Es Doctora en Pedagogía por la Universidad de Barcelona.Trabaja como Profesora en el Departamento de Pedagogía Aplicada de la Universidad Autónoma de Barcelona (UAB). Ha sido coordinadora del Máster en Dirección y Gestión de Centros Educativos de la Universidad de Barcelona. Actualmente, es responsable de la Coordinación Académica del Postgrado y Máster en Dirección de Centros para la Innovación Educativa de la UAB. Ha participado en Congresos nacionales e internacionales, fundamentalmente en temas de Organización, Dirección de Centros Educativos y Desarrollo Organizativo. Ha sido de miembro del Comité Organizador y Científico de varios Congresos nacionales e internacionales.Ha escrito diversas publicaciones en libros y revistas sobre temas de organización, gestión convivencia Supervisión y Dirección de centros. Ha dirigido tesis de Doctorado y de Máster sobre temas de organización, gestión, convivencia Supervisión y Dirección de centros, entre otros. Es miembro del Fòrum Europeu d'Administradors de l'Educació de Catalunya. Actualmente es Profesora Lectora de Universidad de Lleida, España. Email: silva@pip.idl.cat

\section{Serafín Antúnez Marcos}

Catedrático de Universidad en la Facultad de Pedagogía de la Universidad de Barcelona (UB). Departamento de Didáctica y Organización Educativa. Ha ejercido como maestro, director escolar, Profesor Titular de la Escuela Universitaria del Profesorado de la UB, Miembro del Equipo Directivo de esa institución y Director Adjunto del Instituto de Ciencias de la Educación de la UB. Desde el año 1989 dirige el Máster en Dirección y Gestión de Centros Educativos de dicha universidad. Director de Programas de Doctorado. Director, consultor, coordinador y profesor ponente en proyectos internacionales de formación inicial y permanente de docentes, directivos escolares, asesores, supervisores y técnicos de la Administración Educativa en España y en diversos países de Europa e Iberoamérica. Participa asimismo en investigaciones nacionales e internacionales relacionadas con esos campos de conocimiento. Docencia en estudios de grado, maestría y doctorado en diversas universidades españolas y extranjeras. Director desde 1991 de tesis de doctorado y de tesis de maestría sobre temas de organización, gestión, innovación, dirección y supervisión de instituciones educativas. Miembro de comités científicos y ejecutivos en diversos congresos nacionales e internacionales. Ha publicado numerosos artículos y varios libros sobre organización y dirección de instituciones educativas y formación del profesorado. Miembro del Forum Europeo de Administradores de la Educación de España y del Colectivo de Movimientos de Renovación Pedagógica de Cataluña. Email: santunez@ub.edu 